\title{
Creating “Opportunity-Rooms” for Inclusion through Popular Education
}

\author{
Christin Tønseth, Jorun M. Stenøien \\ Department of Education and Lifelong Learning, Norwegian University of Science and Technology, Trondheim, Norway \\ Email: christin.tonseth@ntnu.no, jorun.stenoien@ntnu.no
}

How to cite this paper: Tønseth, C., \& Stenøien, J. M. (2019). Creating "Opportunity-Rooms" for Inclusion through Popular Education. Creative Education, 10, 1456-1474.

https://doi.org/10.4236/ce.2019.107107

Received: February 26, 2019

Accepted: July 9, 2019

Published: July 12, 2019

Copyright $\odot 2019$ by author(s) and Scientific Research Publishing Inc. This work is licensed under the Creative Commons Attribution International License (CC BY 4.0).

http://creativecommons.org/licenses/by/4.0/

\begin{abstract}
In this paper, we take a closer look at five Norwegian initiatives from the Nordic project Folkbildning Norden, which is intended to contribute to a better reception of immigrants. Our question is in what way these initiatives provide "opportunity-rooms" for inclusion. The initiatives underline the recognition of lifelong and life-wide learning by linking informal and formal elements of learning - where the "free and voluntary" are tightly coupled with the "useful and necessary". All the initiatives create inclusion through involvement, networking, trust, belonging, and language learning. The initiatives tell us that different "opportunity rooms" might be important gateways for inclusion in various social contexts. The initiatives also allow for a further discussion about possible advantages and potential of the voluntary sector regarding increasing immigrants' opportunities for inclusion into the society.
\end{abstract}

\section{Keywords}

Norway, Learning, Inclusion, Popular Education, Opportunity Structures, Opportunity Rooms

\section{Introduction}

High rates of immigration highlight the question of inclusion from political and practical perspectives, which places possibilities for learning on the political agenda. Moreover, there is a search for ways that can contribute to fast and successful inclusion in the society. Can initiatives from the voluntary sector and popular education contribute to the inclusion of immigrants in society and the workplace?

Morrice (2014) has indicated several links between learning and migration regarding the adaptation process in a new socio-cultural context. He has highlighted how inclusion depends on a newcomer's cultural context and the spe- 
cific conditions of the migration process. Wildemeersch and Kurantowicz (2011) have indicated that research in adult education that deals with issues of community building often relates to the dominant orientation of restoring social cohesion through the increase of social capital. The authors have also discussed another approach that argues that the experience of the interruption of common sense has a central educative meaning. One challenge might be that popular education is a unilateral process to make the immigrants like natives (Osman, 2013). In addition, Alenius (2016) has found that immigrant engagement in various social groups in transnational environments had widened their perspectives and understanding, enabling them to explore differences in societal conceptions and practices.

In this paper, we discuss five cases that exemplify different initiatives provided by popular education in Norway. According to Pastuhov and Rusk (2017), participation in study circles might express aspects of citizenship as "acting" and "being". Our aim is to use relevant theoretical perspectives to identify and reflect on various elements of inclusion and learning in these initiatives. Our main question is, "in what way might these initiatives provide opportunity rooms for inclusion?"

A short presentation of a political context will form the background for discussing the role of the initiatives for inclusion. In a theorizing part, we first associate inclusion with the concept of "opportunity-rooms". Thereafter we present and clarify the concept of social capital, and finally, we point to the fact that opportunities taken also depend on individual approaches. There is a brief methodical part introducing the presentation of the five Norwegian examples. In the discussion, we direct the attention to how these examples of initiatives can contribute to social meetings, sharing knowledge, and experience and developing new networks. Can you imagine a course design for inclusive opportunity spaces? We will argue that different forms of initiative presented here, opens possibilities for inclusion.

\section{Context for Inclusion Efforts-Policy}

Norwegian immigration and inclusion were recently highlighted in the official report "Integration and trust. Long-term consequences of high immigration" (NOU, 2017). According to this report, the focus of the Norwegian integration regime has gradually moved from a policy of securing basic rights to workpromoting measures. The main strategy for integration is for immigrants to become a part of the workforce, helped by the qualification line of education and employment. This is both a productive and utilitarian line. The common understanding is that employment for as many as possible is necessary to uphold the welfare state. However, immigrants face difficulties in accessing the labour market. The immigrants that are the worst off are those from non-western continents such as Asia and Africa. These immigrants are also the most dependent on social and health services. Even among highly skilled immigrants, the employment rate is still lower than average. This means that many immigrants expe- 
rience a reverse class journey in their new country (Fossland \& Aure, 2011). Refugees do better after a few years. However, there is again a decline in work-life participation after 7 - 10 years, and not all immigrants will ever become part of any educational programs. National statistics indicate that immigrant participation in voluntary organisations is low, and that existent is often related to immigrant organisations (NOU, 2017). This suggests that inclusion might be a continuous process.

One might say that the opportunity structures in the country of immigration restrict habitual possibilities. The concept of opportunity structures is borrowed from Rubenson's (2016) article about lifelong learning for all in Europe. He has aimed to understand the fundamental role that popular education could play in the European Commission's strategy. Rubenson has focused on favourable participation patterns in adult education in Sweden as well as other Nordic countries and on the importance of understanding the context of adult education, such as the impact of the welfare state and other opportunity structures. Opportunity structure refers to the notion that opportunity, the chance to gain certain rewards or goals, is shaped by the way the society or an institution is organized or structured. Such structures provide broadened learning opportunities for groups that traditionally do not seek adult education. Immigrants form one of these groups. Publicly supported popular education provides individuals with access to a form of adult education that can respond to aspirations and needs and is different from formal education or the education and training supplied by employers.

Education is a key to include immigrants into our society, but the form that education takes is also important. More formal learning (organised, structured with formal competence as a goal) is highly recommended for all. Non-formal learning (structured, without aiming for formal competence) might also be recognised and validated. Informal learning (governed by the individual, neither organised nor with a set of objectives in terms of learning outcomes) is also important, as long the learning can be understood according to structured learning outcomes (Alfsen, 2016). However, a great deal of adult learning takes place outside the formal education system. Moreover, research on adult learning demonstrates that different dimensions of skills and key competences are thematised and expressed in the different contexts in which adults participate: family, friends, the workplace, daily activities, leisure activities, practicing, rehearsing, and so on. These soft skills are different from recognised and official qualifications, but might be very important for successful inclusion. Research has indicated that learning also occurs as an unintentional or wider outcome of organised activities, whether the activities themselves have visible learning objectives (Tønseth, 2011).

The recently launched National Competence Political Strategy (2017-2021) (Kunnskapsdepartementet, 2017) has three main goals: good choices for the individual and society, learning in work life, and effective utilisation of competence and strengthening the competence of adults with weak affiliation to work 
life. This strategy document cites voluntary organisations as an important learning area with which popular education (voluntary organizations and adult education associations) the role of supporting eristic which vary from one supplied by many adults are affiliated. The document underlines that organisations, including study associations, offer a wide span of courses and education or learning opportunities. Some courses are directly targeting specific competences demanded in working life, while others help to build basic competences such as language, ability to cooperate, and ability to learn. This description assigns employers. Voluntary organizations' and study associations are institutions for popular education. They offer learning opportunities that can enable and open for inclusion. The following section assesses the alternative or additional role of "bildning", which builds on the ideal of a free and possibly endless process that is combined with an image of an important result-the democratic citizen (Gustavsson, 2016).

\section{Possibility-Rooms for Inclusion}

Language skills are often the first or only key factor mentioned for immigrants and inclusion. However, even with proper language skills and education, immigrants may face difficulties in terms of social and work life inclusion (Fossland \& Aure, 2011). This suggests that language learning is embedded in particular cultural contexts that must be acknowledged for successful inclusion.

In this paper, we have chosen the concept of inclusion. This is because "integration" involves the important values of cross-cultural meeting, relationships, and social participation to a lesser extent. Integration often simply means physical adaptation through increased availability, while inclusion refers to a process and a goal where participation in a social community is built over the cultural differences (Vislie, 2003). We think that inclusion corresponds with the hallmarks of the tradition of popular education.

The concept of inclusion refers to a social process that brings together minorities and majorities in a society (Døving, 2009). This process involves identity, culture, and language elements (Gitz-Johansen, 2006). The combination of social participation and social connectedness is important to capture the essential dimensions of inclusion at work, civic engagement, and involvement in the community (Vandenabeele, Reyskens \& Wildemeersch, 2011). Participation refers to the extent to which the adult takes part in different networks in society (Ekström, Ivanoff, \& Elmstahl, 2013). Connectedness refers to the degree of closeness between the self, other people, the community, and society at large (Lee, Dean, \& Jung, 2008).

Opportunity rooms are meeting places for the exchange of experiences where people can bridge the gap between their experiences and the new culture's opportunity structures. Although Stephen Billett (2001) has based his model of co-participation on workplace learning, we find his model to be useful in settings where communities practice and affordances meet and relate to individual participation and engagement (Figure 1) (Rismark \& Stenøien, 2011). 


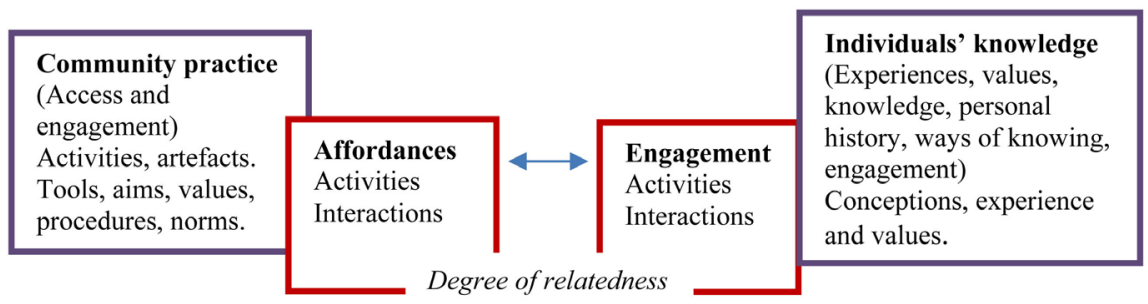

Figure 1. Opportunity rooms-bridging the gaps between individual experiences and opportunity structures in the new culture. Source: inspired by Billett (2001).

In the context of this paper, community practice refers to the voluntary organizations and study organizations that organize initiatives (affordances) based on their practices. The model makes it possible to focus on the initiatives provided by the community (affordances). These are expectations that are based on goals, values, and norms and provide rooms for activities for participation and learning opportunities. The affordances setup structures the activities and possible engagement and learning. When we ask how these initiatives can be opportunity rooms for inclusion, the question involves how the relatedness between these affordances also includes engagement based on individuals' knowledge and experiences. In other words, individuals' backgrounds are included as part of this relatedness. The individual approach and how individuals experience and meet the external world is of great importance for successful inclusion. However, the external surroundings are also important in being inviting to immigrants and granting them access to knowledge, practices, networks, and communities.

Formal education includes all officially approved education that leads to formal competence. Non-formal education includes courses, seminars, and conferences where education is the main purpose of participation, as well as private lessons and lectures that are not included in formal education. In addition, non-formal education includes scheduled periods of organized guidance in the work situation of a colleague, instructor, or supervisor. This is known as "guided on-the-job training". Informal learning is knowledge acquired by adults apart from organized education and training programs (Billett, 2001). One main characteristic of the research on adult learning, both Norwegian and international, is that it has focused separately on the different forms of learning (informal, formal, and non-formal), without emphasizing the relationship between them (Wahlgren, 2012).

In Norway, adult participation in formal and non-formal learning has been relatively stable between 2012 and 2017. In 2017, 60\% of all adults between 25 and 64 years of age have participated in formal or non-formal learning. The participation percentage is equal between men and women. As is expected, the participation rate is highest for those who had the highest level of education (76\%) and lowest for those who had the lowest level of education (40\%) (Statistics Norway, 2017a).

In a labour market undergoing rapid change, employees experience stricter 
requirements for work-related competence. The workplace is an important arena for non-formal education in Norway. In 2017, more than half of the adult population were participating in non-formal education (Statistics Norway, 2017b).

The public sector is one of many providers of adult education in Norway, which offers formal learning at different educational levels. Study associations, voluntary organizations, online schools, and private providers offer formal education as well as informal learning. In 2016, there were 505,000 participants in 45,000 eligible courses arranged by the study associations. Of all participants, $28 \%$ were in the age group 14 - 29 years, $29 \%$ were in the age group 30 - 49 years, and $43 \%$ were 50 years and older. Like all previous years, female participants were the majority. Women accounted for 57\% of all participants in 2016 (Statistics Norway, 2017a).

\section{The Importance of Social Capital}

The initiatives emphasize the importance of social aspects of leaning. This raises the concept of social capital. One important asset for inclusion is social capital. Social capital is important for living conditions, educational outcomes, labor market adjustments, the job search, the integration of ethnic minorities and immigrants, legal compliance, voluntary and collective self-help, human health, and well-being (Narayan \& Prichett, 1999). The creation of social capital has therefore been embraced as a solution for better inclusion processes (Boix \& Posner, 1998). The term social capital is commonly used and linked to concepts such as civil society and social connectedness (Franc \& Borut, 2003). The concept of social capital includes trust, social networks characterized by reciprocity, social and communal values and norms, and commitment to common goods. Social capital can consist of ties between peers and bridges between people with different positions in the society. Social networks play a central role in promoting opportunities for inclusion in the society. Strong social networks are often based on family relations. Social networks are important but might become closed and exclude individuals from the outside world (Fossland \& Aure, 2011). Weak social networks are often based on relations with colleagues and acquaintances who seem to be more open and inclusive regarding building new relations. In this respect, weak social networks provide opportunities for inclusion into wider society (Cocquyt, Doep, Zhu, Greef, \& Vanwing, 2017).

Social capital is a relevant concept partly because it is important to understand the impact that local, relational, and contextual knowledge has on inclusion. In addition, research has demonstrated that social capital is important for learning, and that learning is important for social capital (Field, 2005). Participation in community-based adult education supports the development of social capital and can even contribute to the recovery of lost social capital (MCIntyre, 2012). We therefore expect that the opportunity for building bridges and ties through participation in community-based education to be an important catalyst in the inclusion process. 


\section{Individual Approaches}

We view inclusion as a process where opportunity structures, social capital, and individual approaches interact. The individual approaches are important, and there are several possible positions that individuals can take to approach the challenges of new circumstances. Individuals act differently, and these approaches might define the learning outcome from participation. Some individuals take an awaiting approach towards learning and participation. They become stuck in what they already know and can easily become an outsider to the unknown (Rismark \& Stenøien, 2011). Such individuals suffer from what Horsdal (1999) has named an interpretation collapse. Language becomes one barrier that prevents them from interacting with their surroundings, which keeps them on the outside.

Other individuals take a more active approach to try to understand the new culture (Rismark \& Stenøien, 2011). These individuals can actively use their background as a mirror for contrasting and learning in the new context. An external perspective is taken that involves interpreting events and situations. This position makes it possible to bridge gaps between the known and the unknown and reach a new understanding. Such a position might open a gate to the actual culture for the immigrant. As Bakhtin (1996) has claimed, it is through the eyes of another culture that strange cultures and people can be fully revealed.

The examples of popular education in our sample actualize the interaction between different forms of learning, and how this interaction influences successful inclusions. We try to understand if and how these examples can be opportunity rooms. The following research question is addressed: to what extent and in what way do these initiatives create opportunity -rooms for participation and learning where social capital can arise and that invite the creation of social capital. They can be bridging catalysts and a way of establishing an interplay between insights on local knowledge and culture that gives immigrants the opportunity to have experiences that are relevant in a new context. These examples therefore fulfil the ideas of popular education as well as learning and creating bridges between experiences and external culture (Gustavsson, 2016). In this study, we examine five examples of initiatives that include immigrants in different forms of learning. The following research question is addressed: to what extent and in what way do these initiatives create opportunity rooms for participation and learning where social capital can arise and inclusion can happen?

\section{Method}

The discussion in this paper is based on a Nordic project called Folkbildning Norden. The project is a joint effort between Nordic sister organizations in popular education and is supported by the Nordic council of ministers. The project idea was to analyze what the popular education organizations deem to be successful examples of popular education that assist newly arrived immigrants to learn language, become a part of society, and meaningfully participate in work 
life. In total, the data material contains descriptions of 22 efforts from all Nordic countries. The project analyzed 22 popular education projects in Denmark (5), Norway (5), Finland (5), Iceland (2), and Sweden (5). Cases were selected based on the initiatives that popular education actors have found to be successful examples. Data was generated through a survey in which organizers were asked to provide detailed descriptions of the purpose, design, and implementation of the initiatives. The initiatives in these projects primarily included study activities, but some work-oriented initiatives were also described. Our study is not representative, neither with regard to the selection in the Nordic project nor with regard to the Norwegian popular education organizations' total initiatives to promote learning. They represent a variety of initiatives from the popular education sector.

We investigated the Norwegian cases as part of this Nordic project. The purposes, methods, and values from each case were described and categorized through open coding (Strauss \& Corbin, 1998). In each case, we searched for unique inclusion potential that was linked to the values of popular education. Although the data provides relatively limited insight, each case illustrates valuable experiences regarding learning and inclusion. The material does not give direct information on how the participants in the different examples approach the initiatives or deal with challenges in their new life. However, it is possible is to interpret how the initiatives are set up to meet ideas of popular education and encourage social and cultural inclusion.

\section{The Norwegian Examples}

The five Norwegian examples consist of a mix of initiatives to promote learning and participation where study organizations and voluntary organizations are responsible for the project, either alone or in cooperation. The study organization Folkeuniversitetet (FU) is responsible for providing the "Course in national subjects commissioned by the Directorate of Health". Folkeuniversitetet has also member organizations that are responsible for two other examples. The Norwegian Band Federation (NMF), which arranges the "winter PULSE", and the Norwegian Red Cross, is responsible for "Stella-Red Cross Women's Center". The two last examples are arranged by voluntary associations which are members of the study organization Nature and Environment (NM). The Norwegian Tourist Association (DNT) is responsible for the EMA-project (unaccompanied minor immigrant), and the Norwegian Garden Association (NHS) is responsible for the project "Borderless vegetables and herbs-immigration women's green knowledge". We will provide a further description of these efforts.

\subsection{Aiming for Qualification}

"Qualification for health personnel with education from countries outside the EEA (EØS)" was a pilot project arranged by FU in 2015-2016. In 2017, the course was made into a mandatory authorisation course that sought to help 
health personnel to realise their previous qualifications and competence to work as doctors and nurses. Without the course, these health personnel could only work as unskilled personnel. Folkeuniversitetet was commissioned as one of the two course providers.

In order to participate, previous education must be approved. There is a language demand equal to a $\mathrm{B} 2$ level language test, and a fee that must be paid, although the authorities pay $30 \%$. The course content is largely defined by the Directorate for Health. It contains opportunities to learn about laws and regulations, ethics, and so on, which are important country-specific competences (Fossland \& Aure, 2011). There is a course leader that delivers lectures and administrates the course, and the course ends with an exam.

Hence, this is a form of formal education that concurs with the Norwegian competence policy's strategic aim to directly target the competence demands of work life. However, since the course is mandatory and formalised, it is not recognisable as a typical form of popular education or "folkbilding". Folkeuniversitetet was probably chosen because they were able to offer the course as a decentralized course in seven cities.

This course is useful for this group of professionals' inclusion in work life. However, it is also an example of a barrier because it is a hoop through which the health personnel must jump if they are to obtain a job in accordance with their previous education and competence. As such, this course also represents a structure that provides for a sequential approach to life and learning.

This course provides social capital and a necessary bridge for social and work life inclusion for these professionals. The course is provided by one of the largest adult education organisations in Norway. However, it is not a course that concurs with the ideas of popular education as a form of free, voluntary, and nonformal learning. Hence, this example will serve as a contrasting example in this paper.

\subsection{To Share Music Experiences}

The NMF arranges VinterPULSE every winter holiday to provide an opportunity to experience a corps-like environment and activities. Together with the South African Field Band Foundation, the NMF wishes to allow children and young people to experience a positive winter holiday, regardless of their socio-economic background. The project is called PULSE, and the main target group is children and adults from different cultures without experience with corps music. After the event, the participants reported that meetings between cultures were informative, exciting, and fun.

This project is part of the NMF's overall strategy to make inclusion a core issue in their activities. The main purpose of this arrangement is to build the NMF's competence from within and to focus on youth cooperation with local corps and minority associations. The goal for this cooperation is to increase these associations' knowledge about corps and allow the whole family to experience the activity. 
The instructor team from PULSE and members from RØST (the NMF's regional youth corps and future leaders) functioned as trainees during the project period. The cooperation between the NMF and the South African Field Band Foundations enabled an exchange of music teachers and competences. PULSE also worked during the year with the corps in Oslo with the most immigrant and low-income members.

The NMF's elite corps RØST received firsthand knowledge about South African methodology and cultural expression. These included models and work methods from South Africa with a focus on play-by-ear, dance, and show design. The cooperation between RØST with their traditional Norwegian corps background, marching style, and uniform and the South African PULSE participants led to an exciting cultural meeting that challenged established corps tradition and created bridges between people who live in the community.

This is a complex example that illustrates how the NMF combines strategy and learning. The winter course is therefore one opportunity room for bridging. In addition, the organization itself is also an opportunity room due to the efforts it has made to prepare for and provide the course and how the course is embedded in the organizational structure and culture.

\subsection{Experience Norwegian Nature and Outdoor Life Traditions}

The goal of the EMA initiative provided by DNT is to provide immigrant youth with a taste of common Norwegian outdoor activities. Learning and mastery are some of the expected outcomes of these activities. In addition, the program aspires towards inclusion because the youth may take part in Norway's natural and cultural heritage. The arrangement takes place during the winter holiday, and all the participants (40 youngsters from up to 11 municipalities) are located together in one tourist lodge in Jotunheimen National Park, together with the tour leader and municipal employees. The lodge has all the requisite facilities (manned reception, bathrooms, meeting room, living room, and a dining room with meals served by the kitchen staff). The participants are aged 14 - 19 years, have varied language competence, but are all part of the formal Norwegian education system.

To develop basic skills in traditional Norwegian outdoor life is the expressed purpose of the initiative, such as how to make food outdoors, how to make a fire, how to catch fish, what clothes to wear outdoor. Every activity is adapted to every participant and their needs. All the participants expressed that they achieved major learning outcomes from the initiative, and several of the participants participate every year by tradition. As a result, some of them have undertaken outdoor tours on their own and have become involved with local DNT groups. Some of them have even found employment at the local tourist huts afterwards.

In this course, common Norwegian knowledge and experiences are imparted to young immigrants. The immigrants acquire new experiences while expanding 
on their previous experiences and face new challenges. The course therefore provides opportunities for both non-formal and informal learning as well as peer networking.

\subsection{Multiple and Non-Formal}

The NHS is the voluntary organization behind the initiative "Borderless vegetables and herbs-immigration women's green knowledge". The main targets of this initiative are ethnic minority women, their families, and persons interested in exotic vegetables, cooking, and horticulture. The intention of the initiative is to highlight immigrant women's green knowledge as a resource for the society. The initiative also aims to contribute, inspire, and counsel immigrant women and their families to go outdoors into the local environment and grow their own vegetables and herbs, thereby strengthening their interest in natural diversity and contributing to social integration.

The starting point for this initiative was a team of five immigrant women who completed a competence program in 2013. The five modules that they learned included how to lead one-day-arrangements and how to lecture about themes. The program covered professional knowledge, history of Norwegian cultivation and food culture, and the women's own experiences and history. These women travelled and presented their food culture in one-day-arrangements, festivals, and other arrangements. This team inspired other women to participate and engage, and the various local garden companies performed the local follow-up. The study association NHS has developed a course arrangement based on this experience.

Those who participate in this effort are expected to share knowledge about their food traditions as well as vegetables and herbs. Participants are also expected to acquire presentation skills, learn to make brochures and materials, learn how to work in teams, and develop a book project. The purpose is to provide the immigrant women with a venue for participation and development, for obtaining a sense of achievement by contributing with their own knowledge and traditions, for learning Norwegian culture, and for developing new networks. There is no requirement that participants have prior knowledge. Participation leads to a course certificate.

The activities vary depending on the local conditions and opportunities. One important activity is the one-day-arrangements to which the immigrant women are invited. Further contact between these women and the local garden company is emphasized. The garden company's administration, county department, and local group contribute to the planning, implementation, and subsequent work. Local garden teams throughout the country arrange activities in suitable localities. Courses, meetings, and visitations take place in areas such as meeting rooms, tents, kitchens, and outdoor environments for cultivation and excursion. Everything from recruitment, access to suitable places, and planning is dependent on local connections and cooperation with local organizations. 
The annual evaluation reports describe the efforts as having high levels of participation. Since 2013, these reports have engaged hundreds of participants throughout the country. The activities have resulted in brochures, posters, and a book. The NHS reports this course as a useful example of "folkbildning". The project is low-cost and low-threshold and builds on participants' experiences and engagement. The project also provides local meeting places and offers organized and non-formal training.

The project's focus is on knowledge sharing and learning, and individual experience from different cultures is highly valued. The project aims to increase local social inclusion through networking and traveling. Because the meetings are based on different cultural knowledge, there will be opportunities for networking between people with different cultural backgrounds, thereby increasing inclusion. These activities contribute to the knowledge and experience of the individual and the garden associations.

\subsection{Multiple Meeting Place-Competence Center}

Stella is a competence center for women that is initiated by the Norwegian Red Cross and is located in the organization's premises in Oslo. The Stella project started in 2012 and commenced regular operations in 2015. The target groups are immigrant women and women in general. This meeting place has room for many activities such as internet cafés, courses, counselling, networking, and the café called Stella Kafé. The main aim of Stella is to establish and operate a venue for participation in Norwegian society, work life, and social life; increase psychological and physical health, and develop networks. The center offers counselling, language training in Norwegian and English, social knowledge, workshops and seminars, mentoring, and trainee opportunities. Stella aims to increase female participation in social and work life through competence training, counselling, self-development, networking, and practice.

The center is mostly operated by volunteers: it has three employees, one trainee, and 170 volunteers. It is open on a daily basis through the week, and the volunteers conduct counselling, lead courses, deliver talks, and follow up with participants. When expert knowledge is needed, it is found among volunteers or hired externally. Since 2012, the center has reported more than 7000 visitors, 1590 registered participants, and about 350 new participants each year. As much as $40 \%$ of the volunteers are of non-Norwegian ethnicity, and in 2015, 40 women received language training in Norwegian, networking, and work training. Voluntary competence documentation is provided after 1 year of engagement or half a year's work in the café. Except at the start, recruitment is not necessary. To continue, Stella needs external funding and The Red Cross must attempt to develop close cooperation with business life.

The Stella competence center is showing a strong tradition in offering actual knowledge, developing competence, and offering opportunities outside the formal education system. Volunteers are actively used, participants are an integrated part of the business, and the center offers flexible and participant-driven 
activities. It is vital to have a vision and a strong framework, to trust and communicate with the volunteers at the center as well as provide them with the opportunity and knowledge to operate independently, and to strike the right balance between the volunteer's independence and organizational support.

Stella provides opportunities for different kinds of learning and relation building for those in Oslo or nearby. It is possible to just show up and use Stella as a social meeting place without further engagement, and it is also possible to participate in and define a course or arrangement. One can choose a short or long engagement and obtain work experience. Hence, Stella is a multiple and open learning arena. This enables the building of basic competences, cooperation, and the ability to learn. The center's emphasis on "free and voluntary" also fit with the ideas of popular education.

It would imprecise to use the word "course" as an umbrella term to describe these examples. Several of the opportunities and locations for participation are the result of the combined and intertwined efforts from both study organizations and voluntary organizations in all but one example. That is why we chose to use the term "opportunity rooms" as the umbrella term for these initiatives.

\section{Discussion-Meeting, Sharing and Bridging}

Common language skills are probably the most important competence for promoting inclusion in a society, although there are other important competences also. It is necessary to acknowledge several key competences and provide learning opportunities for each one. However, it is important for knowledge and competences to be formed within a practice that develops ties and bridges, thereby creating social capital.

In the following examples, language learning was not the main intention. Language skills were a requirement for accessing the formal and mandatory course for health workers. At the competence center, language training was one focus area among others and a part of both non-formal and informal learning opportunities. In all the other examples, language learning was not in focus; instead, it was viewed as an opportunity derived from informal learning, which is when immigrants and locals meet and interact. Hence, learning and practicing language skills accrue as secondary benefits from social activities and other forms of learning.

Meeting, accessing new knowledge, sharing knowledge and experiences, and developing new networks are the core opportunity elements in the examples. Three main target groups of immigrants were in focus: young immigrants, women, and professionals. The knowledge areas in focus were related to health work, recreational knowledge, plants and growing, corps music, and so on. These were communicated through different forms for learning. Although it is difficult to capture the outcomes, these examples describe bridging between various forms of learning.

The immediate outcomes that the opportunity rooms were designed for included the sharing of common experiences and the exchange of knowledge. One 
of the winter holiday projects offered corps activities. At winter PULSE, the young asylum seekers had the opportunity to share the experience of outdoor activities. In both cases, there were arrangements that conferred individual and collective experiences.

In two examples, immigrant women were the main target group. One example was a meeting place for women that was open for attendance on a daily basis. The other example was meetings that took place in the local section of the organization. Both offered an opportunity to be active and involved in forming both individual and collective programs, depending on the individual and the level of local interest and engagement. The example that targeted health professionals gave the participants the least freedom to form the program.

Other possible outcomes included the development of personal and interpersonal skills, cooperation with others, and learning to solve problems. These opportunities were offered through different kinds of competence raising, self-development, one-to-one counselling, adjusted courses and activities, and the possibility of voluntary work. These are all useful life skills and are broad outcomes that can meet demand in the labour market and society.

Bernt Gustavsson (2016) has described "bildung" as the individual's ability to relate to other peoples' experiences. It is also about bridging between personal experiences, the background, and external culture. The "folk bildning" - tradition also includes a collective and community-based aspect. To meet, speak, and share is viewed as a catalyst for bridging between personal experiences, the background, and external culture (cf. Billett, 2001). In the health course example, the idea is to expand contextual knowledge in the field. Achieved qualifications are approved as a base to build on, according to normal standards and formal education. In the recreation example, the youngster is given the opportunity to experience and learn how to face challenges on a recreational tour. This forms a base for bridging.

At Stella, participation and learning can vary significantly. However, there are opportunities to be involved, initiate courses, meet others, and experience cultural exchange. The green knowledge example has cultural exchange built in. This is the case for the women who were trained to talk about green knowledge; that opportunity still exists in the locally provided activities. The corps example has inclusion built into the organization of the project. The planning and preparation work that leads up to the arrangement includes opportunities for bridging. Whether the local partners manage to fulfill this idea and provide opportunities for bridging is not for us to decide.

Experiencing otherness is at the core of being an immigrant. Both "bildning" and "bridging" have to do with experiencing otherness. Ties and bridging are two of social capital's important dimensions. Relation is an element in both concepts. Ties related to networking-meaning relations between people. Bridging is about making connections between the elements that are unknown to each other. Both the experience of relating to others and bridging are relevant to experiencing otherness. It is the way one experiences otherness (picture 
strangeness or as an interaction) and thereby relates and bridges that forms the base of learning and inclusion.

We have established that the first example with the health personnel adheres to the idea that courses provided by the study associations might target specific competence demands in working life. In one sense, this is far from the free and voluntary ideal of learning. However, in spite of this, if we understand the course from the perspective of lifelong learning and living, this course may be one of the many learning journeys that are required to join society as a full citizen. Along with the idea that popular education can make connections to work life, the Stella competence center also comes close. Trainee jobs and working in the café result in experience and documentation. In other examples, learning and competence appear more as a broader outcome, for example through experience with planning and arranging events.

Voluntary organizations were involved in the provision of opportunities to become part of a community and creating networks. Involvement in different activities enabled opportunities to connect and develop relations. In the green knowledge example, there were other opportunities for building ties. For example, experience with arranging activities and speaking at arrangements. Participants also had the opportunity to meet people with similar interests at different localities. For those who were involved in the locally arranged activities, there were opportunities for local community building. The youngsters at the DNT tour were introduced to Norwegian culture, knowledge, and experience. Hence, this course provided experiences that may fuel the opportunity to bridge between personal experiences, backgrounds, and new experiences. It was also possible to establish peer relations. The core of the other winter course pertaining to corps music and experience was the opportunity to network and exchange music forms. These courses provide participants with the opportunity to exchange cultures.

One interesting outcome of the participation and further engagement is how building ties and networking often develop as wider and unspoken outcomes. All of the examples create opportunity rooms for building social networks. Given that social capital consists of trust, social norms, and shared values characterized by reciprocity and commitment to the common good, these examples promote confidence, trust, and common values. By bridging and creating new networks, favorable terms and conditions are in place for increasing social capital as a lubricant in the machinery of the society that promotes inclusion. It is however difficult to say if these networks are useable for accessing work life.

\section{Course Design Including Opportunity Rooms}

Connecting teaching and learning to a positive local context provides a much-needed relevance and meaning to the learning process. Not only does it help the learner to develop a better understanding of their environment, culture, and language, but it also makes the learning process positive, real, and active for 
those involved. Active citizenship is about active engagement with the civic issues in the local cultural context and taking responsibility for them. This is one of the important goals of the politics of inclusion. To accomplish this, we need to find a way to prepare and involve immigrants. This can be achieved by using civic issues and other important community issues as learning contexts.

The core of the inclusion concept is to increase immigrant social capital by using benefits to motivate participation in the community. Most of the examples described in our paper involved the design of opportunity rooms for learning. By designing opportunity rooms, we intend to choose a relevant environment for learning and thereby increase the possibility for synergies between the affordances (Billett, 2001) and the participants' interests, needs, conditions, and assumptions. One possible outcome of this synergy is increased social capital for all (Norwegian Research Council, 2005).

Establishing environmental factors are included as elements in all modern course design taxonomies (Biggs \& Tang, 2001), but more attention has been paid to environmental factors and contexts in recent times. To develop learning design principles (a taxonomy) that involve possibility-driven design rather than a problem-driven design is a relatively new angle (Desmet \& Hassenzahl, 2012). The main value of possibility-driven design stems from a more positive and optimistic view of everyday life; on individuals' subjective well-being, positive relations, meaning, and engagement. Thus, this form of design is not focused on making the lives of miserable people less miserable by solving their problems; instead, it is focused on creating opportunities to help people flourish. In general, possibility-driven design is particularly promising when it targets the subjective well-being of individuals and communities. Possibility-driven design can add to or be a new way of understanding popular educational initiatives.

\section{Conclusion}

The initiatives described in this paper indicate that choosing a local context can be viewed as an opportunity room for learning. Opportunity rooms provide a wide range of relevant, immediate, and broader outcomes. The purpose of using opportunity rooms as a medium for learning is to use real-life experiences as a pedagogic platform. This platform gives immigrants an opportunity to experience how meetings and sharing experiences are viewed as immediate outcomes in an integrated social manner.

According to a possibility-driven course design, opportunity rooms for learning create activities that contribute to the immigrants' well-being, commitment, interest, and social interaction. We believe that moments of engagement, interest, and social meetings represent promising entry points to language learning, the creation of social capital, and bridging and inclusion. More importantly, these moments provide an opportunity to apply individual lessons to everyday life in Norway.

Our findings substantiate the relevant studies presented in the introduction; 
the studies have emphasized the link between immigrant culture and identity on one hand and the new cultural context on the other. Our findings also underpin the importance of social networks as a catalyst to explore the new culture and country. Hence, the term "opportunity rooms" is a particularly relevant starting point and a useful dimension. Some questions that we always should ask include the degree to which the immigrant becomes a recipient as well as how immigrant knowledge and styles of action can become resources to mirror local knowledge and culture and increase common social capital.

\section{Conflicts of Interest}

The authors declare no conflicts of interest regarding the publication of this paper.

\section{References}

Alenius, P. (2016). Informal Learning Processes of Migrants in the Civil Society: A Transnational Perspective. European Journal for Research on the Education and Learning of Adults, 7, 41-55. https://doi.org/10.3384/rela.2000-7426.rela9072

Alfsen, C. (2016). Country Report Norway. 2016 Update to the European Inventory on Validation of Non-Formal and Informal Learning. Thessaloniki, Greece: CEDEFOP. https://cumulus.cedefop.europa.eu/files/vetelib/2016/2016_validate_NO.pdf

Bakhtin, M. M. (1996). Speech Genres and Other Late Essays. Austin, TX: University of Texas Press.

Biggs, J., \& Tang, C. (2011). Teaching for Quality Learning at University. What the Student Does (4th ed.). Berkshire: Society for Research into Higher Education \& Open University Press. New York: Open University Press.

Billett, S. (2001). Learning through Work: Workplace Affordances and Individual Engagement. Journal of Workplace Learning, 13, 209-214. https://doi.org/10.1108/EUM0000000005548

Boix, C., \& Posner, D. N. (1998). Social Capital: Explaining Its Origins and Effects on Government Performance. British Journal of Political Science, 28, 686-693. https://doi.org/10.1017/S0007123498000313

Cocquyt, C., Doep, N. A., Zhu, C., Greef, M. D., \& Vanwing, T. (2017). Examine Social Inclusion and Social Capital among Adult Learners in Blended and Online Learning Environments. European Journal for Research on the Education and Learning for Adults, 8, 77-101. https://doi.org/10.3384/rela.2000-7426.rela9111

Desmet, P. M. A., \& Hassenzahl, M. (2012). Towards Happiness: Possibility-Driven Design. In: M. Zacarias, \& J. V. Oliveira de (Eds.), Human-Computer Interaction: The Agency Perspective (pp. 3-27). New York: Springer. https://doi.org/10.1007/978-3-642-25691-2__1

Døving, C. A. (2009). Integrering: Teori og empiri. Oslo: Pax Forlag.

Ekström, H., Ivanoff, S. D., \& Elmstahl, S. (2013). Does Informal Support Influence Social Participation of Fractured Elderly People? Archives of Gerontology and Geriatrics, 56, 457-465. https://doi.org/10.1016/j.archger.2012.11.010

Field, J. (2005). Social Capital and Lifelong Learning. Bristol: Policy Press. https://doi.org/10.1332/policypress/9781861346551.001.0001

Fossland, T., \& Aure, M. (2011). When Higher Education Is Not Enough: Integration of 
Highly Educated Immigrants in the Labour Market. Sosiologisk tidsskrift, 19, 131-152.

Franc, A., \& Borut, R. (2003). Social Capital: Recent Debates and Research Trends. Social Science Information, 42, 155-183. https://doi.org/10.1177/0539018403042002001

Gitz-Johansen, T. (2006). Den multikulturelle skole: Integration og sortering. Fredriksberg: Roskilde Universitetsforlag.

Gustavsson, B. (2016). The Idea of Democratic Bildung: Its Transformation in Space and Time. In: A. M. Laginder, H. Nordvall, \& J. Crowther (Eds.), Popular Education, Power and Democracy (pp. 35-49). Leicester and Cardiff: NIACE.

Horsdal, M. (1999). Livets fortellinger-en bog om livshistorie og identitet. København: Borgen.

Kunnskapsdepartementet (2017). Nasjonal Kompetansepolitisk Strategi 2017-2021 (National Political strategy on Competence). Oslo: Rapport fra Kunnskaps Departementet.

Lee, R. M., Dean, B. L., \& Jung, K. R. (2008). Social Connectedness, Extraversion, and Subjective Wellbeing; Testing a Mediation Model. Personality and Individual Differences, 45, 414-419. https://doi.org/10.1016/j.paid.2008.05.017

McIntyre, J. (2012). The Development and Recovery of Social Capital through Community-Based Adult Learning. International Journal of Lifelong Education, 31, 607-621. https://doi.org/10.1080/02601370.2012.693955

Morrice, L. (2014). The Learning Migration Nexus: Towards a Conceptual Understanding. European Journal for Research on the Education and Learning of Adults, 5, 149-159. https://doi.org/10.3384/rela.2000-7426.rela9044

Narayan, D., \& Prichett, L. (1999). Cents and Sociability: Household Income and Social Capital in Rural Tanzania. Economic Development and Cultural Change, 47, 871-897. https://doi.org/10.1086/452436

Norwegian Research Council (2005). Social Capital. A Report from the Evaluation Committee. Oslo.

NOU (2017). Integrasjon og tillit. Justisdepartementet, 2017. Integration and Trust. Long-Term Consequences of High Immigration (No. 2).

Osman, A. (2013). Popular Education in the Service of Integration. In: A. M. Laginder, N. Henrik, \& C. Jim (Eds.), Popular Education, Power and Democracy. Leicester and Cardiff: NIACE.

Pastuhov, A., \& Rusk, F. (2017). Citizenship as Individual Responsibility through Personal Investment-An Ethnographic Study of Study Circle. European Journal of Research on the Education and Learning of Adults, 9, 1-14. https://doi.org/10.3384/rela.2000-7426.relaojs99

Rismark, M., \& Stenøien, J. M. (2011). Polske sykepleiere i Norge. Liv og læring i et nytt Samfunn. In: S. Tøsse, L. Aarsand, E. Håland, \& C. Tønseth (Eds.), Voksne, læring og kompetanse. Oslo: Gyldendal akademisk.

Rubenson, K. (2016). Towards Lifelong Learning for All in Europe: Understanding the Fundamental Role Popular Education Could Play in the European Commission's Strategy. Chapter 2. In: A. M. Laginder, H. Nordvall, \& J. Crowther (Eds.), Popular Education, Power and Democracy (pp. 14-34). Leicester and Cardiff: NIACE.

Statistics Norway (2017a). Adult Learning. https://www.ssb.no/utdanning/statistikker/vol

Statistics Norway (2017b). Dette er Norge 2017. Tall som forteller. Report. http://www.ssb.no/befolkning/artikler-og-publikasjoner/dette-er-norge-2017

Strauss, A., \& Corbin, J. (1998). Basics of Qualitative Research: Techniques and Procedures for Developing Grounded Theory (2nd ed.). Thousand Oaks, CA: Sage. 
Tønseth, C. (2011). Voksne i læring. Identitetskonstruksjon i lys av Kompetansereformen. Ph.D. Dissertation, Trondheim: Norwegian University of Science and Technology.

Vandenabeele, J., Reyskens, P., \& Wildemeersch, D. (2011). Diverse Views on Citizenship, Community and Participation. Exploring the Role of Adult Education Research and Practice, European Journal for Research on The Education and Learning for Adults, 2, 193-208. https://doi.org/10.3384/rela.2000-7426.rela0017

Vislie, L. (2003). On Integration to Inclusion: Focusing Global Trends and Changes in the Western European Societies. European Journal of Special Needs Education, 18, 17-35. https://doi.org/10.1080/0885625082000042294

Wahlgren, B. (2012). Voksnes læreprosesser. Kompetanseutvikling i uddannelse og arbejde. København: Akademisk forlag.

Wildemeersch, D., \& Kurantowicz, E. (2011). Editorial: Adult Education and the Community. European Journal for Research on the Education and Learning of Adults, 2, 129-133. https://doi.org/10.3384/rela.2000-7426.relae3 